\title{
NPL Usability Services
}

\author{
Nigel Bevan \\ National Physical Laboratory \\ Teddington, Middlesex, TW11 0LW, UK \\ Nigel.Bevan@npl.co.uk
}

KEYWORDS: Usability evaluation, metrics, usability engineering, standards.

NPL Usability Services is headed by Nigel Bevan, and currently has five other permanent staff with varied backgrounds in computing, psychology and HCI (Cathy Thomas, Ian Curson, Owen Daly-Jones, Richard Lakin and Andy Harry).

NPL Usability Services operates as a commercial consultancy within the Information Systems Engineering Branch at the National Physical Laboratory. The National Physical Laboratory is the UK's national standards laboratory, owned by the Department of Trade and Industry, and since 1995 operated by NPL Management Ltd, a wholly owned subsidiary of SERCO Ltd.

NPL Usability Services evolved from the HCI Group at NPL, a pioneering group formed in the 1960s by Chris Evans. Chris Evans, author of "The Mighty Micro", investigated how computers could be made easy enough for the public to use. One application used a Teletype connected to a time-sharing computer to interview patients in doctors' surgeries. Patients actually preferred interaction with a Teletype to a real doctor, and alcoholics were found to be considerably more honest when reporting their drinking habits to a computer!

Nigel Bevan joined the group at this time, and worked on a simple language for scripting medical interviews. This evolved into the popular Microtext authoring language, widely used by teachers in the UK to produce their own educational applications on the BBC Micro in the early 1980s.

\section{MUSIC PROJECT}

In 1990 NPL took the technical lead in the European ESPRIT MUSiC project: Measurement of Usability in Context. This was a three year project with the ambitious aim of turning usability from a broad aspiration into a quantifiable objective. The methods developed by MUSiC are still the only integrated approach to usability measurement. They operationalise ISO 9241-11: Guidance on Usability, which defines usability as the extent to which a product can be used by specified users to achieve specified goals with effectiveness, efficiency and satisfaction in a specified context of use.

The MUSiC methods provide a precisely specified and documented procedure for carrying out user-based usability evaluation providing both measures and design feedback. Usability Context Analysis (developed in conjunction with HUSAT) is a structured method for identifying the relevant characteristics of users, tasks and environments. The Performance Measurement Method specifies how effectiveness and efficiency can be measured in a valid and reliable way, and is supported by the DRUM software tool for annotating video tapes. SUMI (developed by University College Cork) provides metrics for user satisfaction.

A major advantage of the methods is that they are sufficiently well documented to allow NPL to train organisations without previous experience of usability in their use. Many organisations find that the ability to specify usability requirements and evaluate whether they have been met is an attractive starting point for introducing usability into design. NPL offers a package of training and assistance in the use of MUSiC methods leading to certification of competency in their use. NPL has provided usability tools, training and services based on MUSiC to over 40 organisations worldwide. Clients have included financial services, government departments and developers of multi-media kiosks.

The tools have been adapted to meet a wide variety of organisational requirements. The challenge is now to place them in the broader context of user-centred design, so that an organisation can select the methods best-suited to the skills, development environment, and individual project. The ability to set and evaluate usability goals provides an overall framework for this process.

\section{TECHNOLOGY TRANSFER}

The emphasis at NPL continues to be on technology transfer of state-of-the art tools. Achieving industrial uptake is as big a challenge as the original tool 
development. The two major contributions that NPL is making to this process are to incorporate usability into standards for ergonomics and software engineering, and to set up a network of European Usability Support Centres.

NPL is actively contributing to the new ISO 13407 Human Centred Design standard, and is incorporating the principles of MUSiC and ISO 9241-11 into ISO 14598-1: Software Product Evaluation, and ISO 91261: Software Quality Characteristics (the latter three standards are edited by Nigel). ISO 14598-1 identifies the quality of a product in use as the highest level ohjective of software product design. Quality in use. mcasured hy effectiveness, efficiency and satisfaction, is a generalisation of the approach to usability in ISO $9241-11$. thus making usability the prime design objective in software engineering!

The EC MAPI (MUSiC-Assisted Process Improvement) project (Sep 95 - Dec 96) applied and extended the methods developed in the MUSiC project to a range of trial applications across Europe. One of the outputs of the project was a cookbook of user-centred design methods produced in conjunction with the UK Inland Revenue for use in their software development process.

\section{EUROPEAN USABILITY SUPPORT CENTRES}

MAPI provided a useful contribution to the more ambitious INUSE project (Jan 96 - Dec 97, managed by NPL) which has set up a network of Usability Support Centres for the European information engineering industry. INUSE has produced an information pack which includes guides to: user-centred design, usability validation and an introduction to multi-media design (these can be down loaded from the INUSE web site). A co-ordinated service incorporating common core methods is being provided by centres including NPL, HUSAT (Loughborough), Lloyds Register (London), University College Cork, Fraunhofer IAO (Stuttgart), SINTEF (Oslo), Nomos Management (Stockholm), and other usability consultancies in Europe (see Figure 1).

INUSE is complemented by the RESPECT project (Requirements Engineering and Specification) which is also managed by NPL with the longer term objective of producing a co-ordinated set of methods for user-based requirements analysis. It has many of the same partners as INUSE, and the methods are expected to be exploited by INUSE. The challenge in RESPECT is to integrate $\mathrm{HCI}$ methods for user requirements with conventional requirements engineering methods.

NPL plans to continue the mix of research and consultancy, working together with other centres of expertise in usability to produce the most appropriate methods and tools to enable industry to develop products and systems which meet the needs of their users.

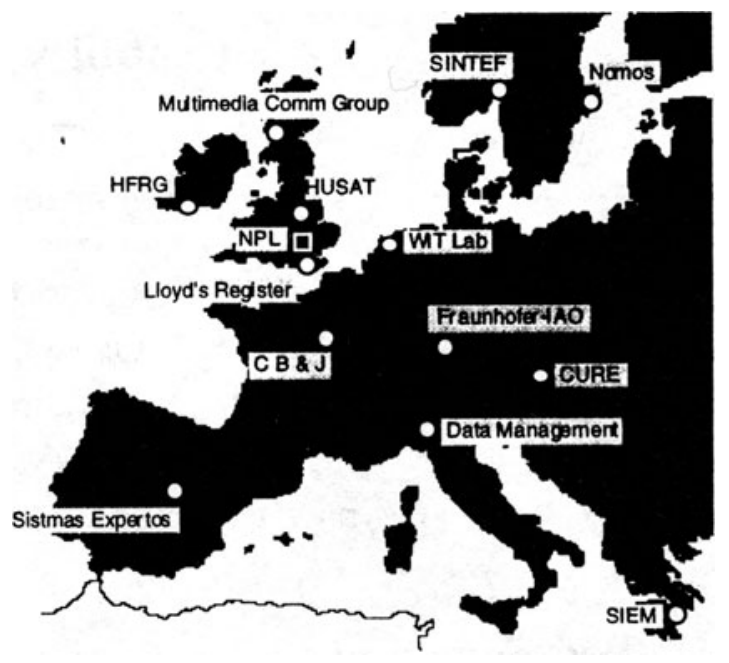

Figure 1. European Usability Support Centres

\section{RECENT PUBLICATIONS}

Bevan N (1995) Measuring usability as quality of use. Journal of Software Quality, 4, 115-130.

Bevan N (1995) Usability is quality of use. In: Anzai \& Ogawa (eds) Proc. 6th International Conference on Human Computer Interaction, July 1995. Elsevier.

Bevan N (1995) Human-Computer Interaction standards. In: Anzai \& Ogawa (eds) Proc. 6th International Conference on Human Computer Interaction. July 1995. Elsevier.

Bevan N and Macleod M (1994) Usability measurement in context. Behaviour and Information Technology, $13,132-145$.

INUSE (1996) see http://www.npl.co.uk/inuse

ISO (1996) ISO/IEC. DIS 14598-1 Information Technology - Evaluation of Software Products - Part 1 General guide.

ISO (1997a) ISO DIS 9241-11 Ergonomic requirements for office work with visual display terminals (VDT)s Part 11 Guidance on usability.

ISO (1997b) ISO DIS 13407 User centred design process for interactive systems.

ISO (1997c) ISO/IEC CD 9126-1 Software quality characteristics and metrics - Part 1: Quality characteristics and sub-characteristics.

Macleod M, Bowden R and Bevan N. (in press) The MUSiC Performance Measurement Method. Behaviour and Information Technology.

Thomas C and Bevan N, eds (1995) Usability Context Analysis Guide V 4. National Physical Laboratory, Teddington, UK. 